\title{
Challenges to Implement Disaster Risk Reduction in Schools of Developing Country: Study on Dhaka City, Bangladesh
}

\author{
Md Mostafizur Rahman ${ }^{1, ~ *, ~ I r t i f a ~ A l a m ~ N a b i l a ~}{ }^{1}$, Farhana Islam², Farah Tasnim², Saba Tabassum ${ }^{2}$, \\ Kamrun Nahar Tanni ${ }^{2}$ Tuly Roy ${ }^{2}$
}

Department of Disaster and Human Security Management, Bangladesh University of Professionals, Mirpur Cantonment, Dhaka, Bangladesh

Email address:

amimostafiz@gmail.com (Md M. Rahman)

${ }^{*}$ Corresponding author

\section{To cite this article:}

Md Mostafizur Rahman, Irtifa Alam Nabila, Farhana Islam, Farah Tasnim, Saba Tabassum, Kamrun Nahar Tanni, Tuly Roy. Challenges to Implement Disaster Risk Reduction in Schools of Developing Country: Study on Dhaka City, Bangladesh. International Journal of Sustainable Development Research. Vol. 6, No. 2, 2020, pp. 37-42. doi: 10.11648/j.ijsdr.20200602.13

Received: April 27, 2020; Accepted: May 20, 2020; Published: May 29, 2020

\begin{abstract}
Disaster has become a frequent phenomenon in today's world and is affecting many worlds' population. The urban areas are highly vulnerable to hazards as urban population is increasing rapidly. Dhaka, the capital city of Bangladesh is in high risk of earthquake, fire hazards, water logging etc. The study has been carried out to ascertain the challenges to implement the Disaster Risk Reduction in the schools of Dhaka city focusing the urban disaster such as earthquake and fire hazard. DRR integration in education system has ensured safe school facility for school going children as well as reducing the risk of community through school-community cooperation. This study follows the Comprehensive Global School Safety Framework, (GADRRRES) to find out the school preparedness and emergency management plan. Mixed method was carried out to collect and analysis data from students, their parents, teachers and staff about the condition of the DRR practices in education, plans and the challenges to implement DRR through FGD, semi-structured questionnaire survey. SWOT analysis has been conducted to understand the current condition of DRR practice in schools of Dhaka city. It has been observed that the respondents have little knowledge about DRR, and most of the schools don't have enough DRR practice and plan. Although DRR is integrated in curricula, the schools do not practice DRR exercises and trainings. A school management plan has been proposed to improve the current condition; thereby the schools of Dhaka city can be prepared for future disaster.
\end{abstract}

Keywords: Disaster Risk Reduction, School, Preparedness, Urban Disaster, Developing Settlement

\section{Introduction}

Disaster is the result due to the interaction of hazardous events with the community's exposure and vulnerability [9]. It disrupts the normal activities of the community or society. Education, knowledge and awareness are important to enhance the ability to reduce losses from natural hazards, as well as the coping capacity to respond to and recover effectively from extreme natural events when they do, inevitably, occur [20]. Disaster risk reduction (DRR) contains the principles and strategies to reduce the probability of hazard to turn into disaster. It is difficult to stop natural hazards to occur. In past years, 302 hazards resulted in disasters that claimed almost 30,000 lives, affected 206 million people and inflicted damages worth an estimated US\$366 million [17]. In 1998-2017 it 1.3 million people died where 4.4 billion were injured for disaster [18]. The economic losses in this period were US\$ 2.9 trillion [7, 18]. These losses may lead to severe due to the recent pandemic disease COVID-19 [5].

In these events of disaster, children are the most affected group. In most cases schooling systems has disrupted and affect the fundamental right of children, the right to education. Developmental gains in education are reversed with the damage or destruction of school facilities, the prolonged disruption of education, limited access to schooling, and decreased education quality. However, the chances of hazard to turn into disaster can be reduced, which 
is the disaster risk, by reducing community's vulnerability. Moreover, this vulnerability can be determined by the community's physical, social, economic and environmental factors. If we can get the information of these factors, we can understand the challenges to reduce certain disaster risk. This study focuses on these factors to determine the school's vulnerability and the challenges to reduce those vulnerabilities. School can act as multipurpose system considering disaster risk, where community can get benefits from school in several ways.

WHO [19] estimates that $30-50 \%$ of fatalities arising from natural hazard events make severe effect on children. It is urgent needs to provide disaster risk-free environment for the children. Education is a significant mechanism through which children can take part in disaster risk reduction (DRR) [2]. In the universal commitment for DRR, Schooling has always been one of the priorities, as expressed in the "Yokohama Strategy" [16], "the Hyogo Framework for Action 2005-2015" [8] and "the Sendai Framework for Disaster Risk Reduction 2015-2030" [17]. Whole community and the nation can be prepared enough if we can prepare our school children properly. Extensive efforts have also been tried to assimilate DRR in the education sector [10]. Mainstreaming Disaster Risk Reduction through education can be instrumental in building the knowledge, skills, and attitudes necessary to prepare for and cope with disasters, as well as in helping learners and the community to return to a normal life [12].

Disaster is one of the main barriers for development in developing country. Development without considering DRR can never be sustainable; rather it can exacerbate the existing disaster or create a new one. Bangladesh, one of most disaster affected countries [3], has the history to fight several types of disaster. It has long coastal line with high density of population. Coastal people have experienced several meteorological hazards. People have migrated to the capital city, increased the exposure of urban hazards. Dhaka city is one of most vulnerable cities due to the lack of awareness, lack of policy and the policy implementation, lack of enough training etc. It has been reported frequent several disaster incidents in Dhaka city $[1,3,4,6,13,14]$. However, people have migrated here for the employment opportunity, medical and education facilities. Many government and private schools have been constructed for the demand of this high population. High exposure and high vulnerability make these schools children force to live in high disaster risk environment. Considering these, it becomes urgent need to understand if these schools follow DRR plan and practice to prepare for any future disaster. This study has intended to understand the existing DRR plan and practices in schools of Dhaka city, Bangladesh.

\section{Materials and Methods}

\subsection{Study Area}

School locations were selected considering the exposure and vulnerability of the locations and the community. Mirpur area of Dhaka is in the most destructive liquefaction zone. The projected levels of liquefaction damage likely to be caused in Dhaka in the event of an earthquake [15]. Also, narrow road and fragile infrastructure make Mirpur more vulnerable for fire and earthquake. Banasree and Dhanmondi are also vulnerable areas of Dhaka city. Old Dhaka is one of the most vulnerable areas in the world especially for earthquake and fire incidents due to the high density of population, unplanned structural development. Considering all these, schools from Mirpur, Banasree, Dhanmondi and Old Dhaka (around Lalbagh area) were selected to collect data.

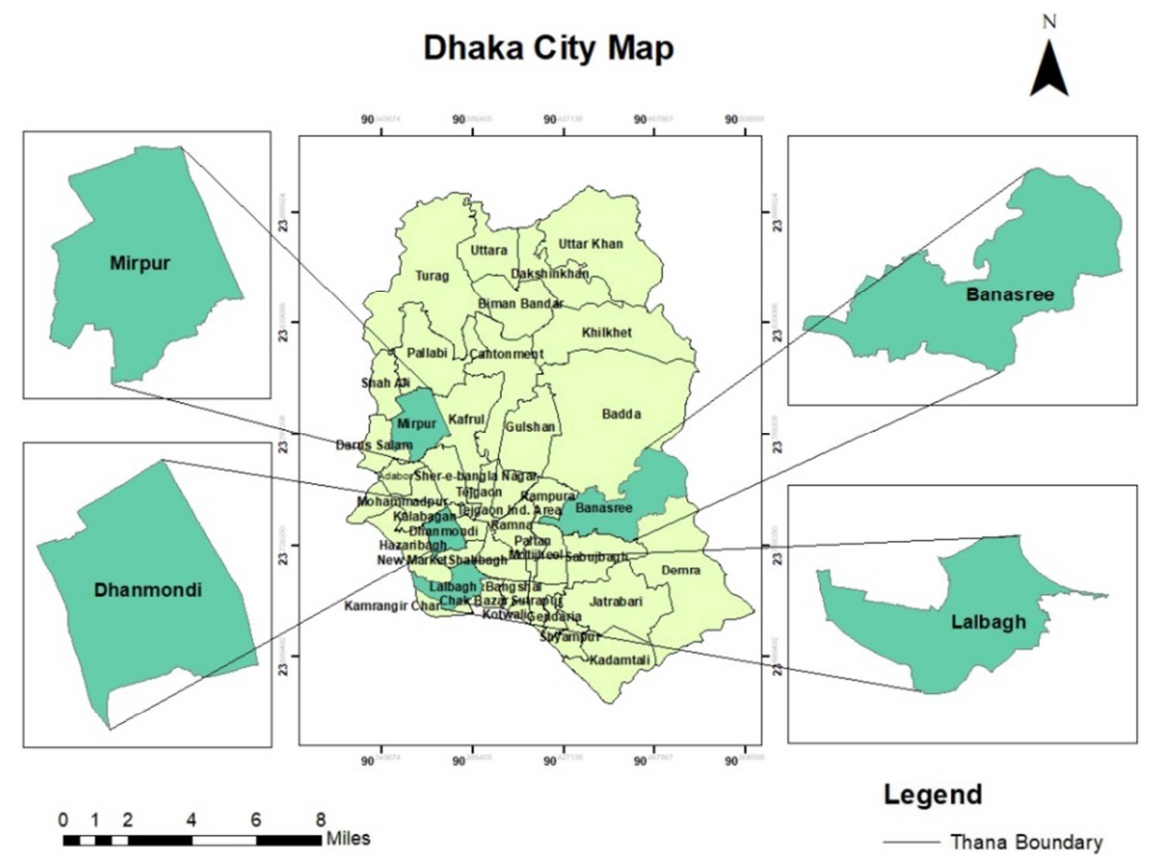

Figure 1. Dhaka city map with study areas (Source: Author, 2020). 


\subsection{Data Source and Methodology}

Both qualitative and quantitative methods were applied for this study. The targeted respondents for this study were school's students, school administrative bodies and the parents. Mixed data were collected from both primary and secondary sources.

Several qualitative data collection tools were applied. Questionnaire survey with interview was carried out based on group categories: School children, parents, teachers, adjacent community, administrative bodies etc. Focus Group Discussion (FGD) was conducted with both parents and teachers as well. Practical observation was made to get information around the schools and to check the availability of structural DRR measures in schools. Interactive presentation session was conducted, where Question-Answer session had separate session with a purpose of getting to know the DRR knowledge practiced in schools.

\subsection{Theoretical Framework}

Comprehensive School Safety is defined to drive the worldwide initiative for safe schools from three pillars. These are i) Safe Learning Facilities, ii) School Disaster Management and iii) Risk Reduction and Resilience Education. The structure is lined up with the Sustainable Development Goals (2015-2030) and the Sendai Framework for Disaster Risk Reduction needs for activity and pointers for the instruction area.

Comprehensive school safety (CSS) framework [11] was thoroughly followed to investigate the current situation of school's safety plan of Dhaka City. The central focus of the investigation complied school building's facilities, disaster management activities and DRR education.

To get insight to the upper criteria; a plan was made as followed -

I. Safe Learning Facilities: In this part of CSS, safe site selection, building codes, building design, water sanitation and hygiene etc. were investigated.

II. School Disaster Management: Activities conducted by school management bodies to reduce disaster risk were considered.

II. Disaster Risk Reduction Education: Child-centered learning, education for sustainable development, teacher training and staff development, conflict sensitive education etc. were explored.

As the Comprehensive School Safety addresses the need for safe learning facilities in a risk-free environment; this study will be carried out depending on three pillars of CSS largely.

\section{Results and Discussion}

Dhaka is one of the most densely populated and unplanned cities in the world. The soil is weak and prone to liquefaction. The infrastructures are made of highly flammable materials which are vulnerable to fire incidents. Most of the infrastructures do not follow building code and are in risk of collapse due to earthquake. The study found that almost all the schools of studied areas are vulnerable. The schools do not follow building code, inadequate amount of training and drill available, poor school safety indicator values etc. By analyzing the data of the four study areas the challenges to implement DRR in schools are discussed in the report.

\subsection{School Category}

Total 52 schools were selected randomly to distinguish DRR practices and difficulties to execute DRR in schools (Table 1).

Table 1. Number of Schools Selected for Survey in Dhaka City.

\begin{tabular}{lll}
\hline Area & Number of Schools & Government Schools \\
\hline Mirpur & 20 & 3 \\
Banasree & 10 & 0 \\
Dhanmondi & 12 & 4 \\
Old Dhaka & 10 & 2 \\
\hline
\end{tabular}

\subsection{DRR Education and Exercise}

DRR training programs are allotted for teachers but in a very inadequate manner (Figure 2). The schools of Old Dhaka and Dhanmondi show an attempt in this sector. Disaster management has been integrated in school curriculum for students; however not in enough portions. As previously stated, after several fire tragedies schools of Old Dhaka have experienced some events funded by both Government and NGO; although not in a satisfactory quantity. (Figure 3) depicts the insufficient amount of drill exercise conducted annually or biannually by the schools of Dhaka especially for fire incidents. As per respondents, most of these exercises are Government funded.

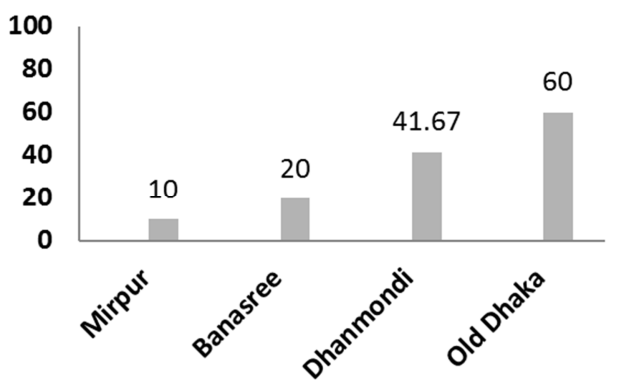

Figure 2. DRR Education/Training (\%).

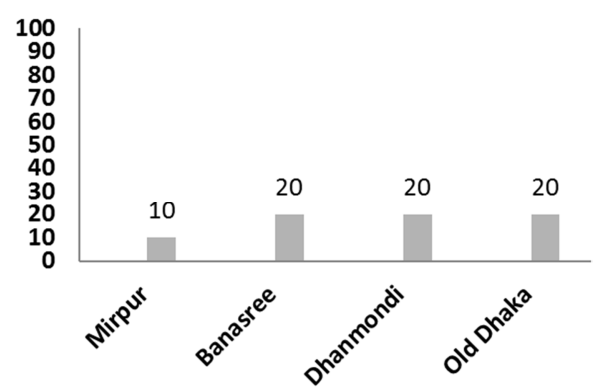

(Source: Field survey, 2020)

Figure 3. Drill Exercise (\%). 


\subsection{School Safety}

Figure 4 portrays the overall school safety indicator values (\%) for the schools in Dhaka city. Respondents (Students, parents and teachers) in surveyed area show the good percentage of the requirement about school safety.

However, the other indexes show poor DRR structural and nonstructural practices in schools. It shows complicated structure of DRR practice where people are concerned about the disaster risk and disaster risk reduction practice. The community participation in drill is inadequate and around $47 \%$ of the respondents has knowledge on community-school interaction for better preparedness. According to the respondents, emergency plan, earthquake safety measures, fire safety measures are barely available in the studied schools. There are certain challenges hinder the way to follow the practices.

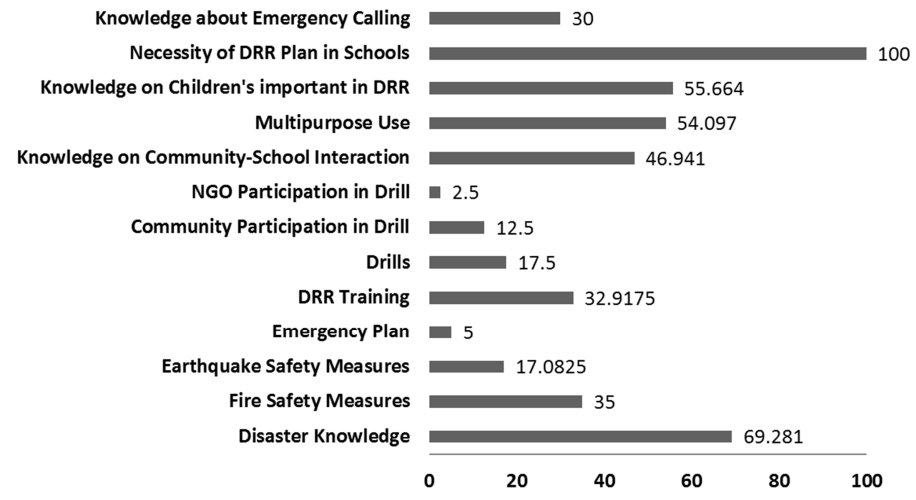

Figure 4. School Safety Indicator Values for schools in Dhaka city (Source: Field survey, 2020).

\subsection{Challenges for DRR Implementation}

As mentioned above some challenges create impediment in the implementation of Disaster Risk Reduction practices in schools. The major challenges that have been pointed out by the respondents are given in (Figure 5).

It has been found that most of the people directly or indirectly link with the schools have knowledge regarding disaster. But there is a complicated gap between their understanding and actual DRR practices in schools.

While DRR is the most prominent activity to reduce the loss of assets and life; lack of policy can be a real drawback to execute it to school level. Most respondents (about $91.67 \%$ ) believe this to be the actual reason of the absence of DRR practice in schools. Though there are some policies regarding DRR, which are in limited portion. The respondents are not aware of it as the policies do no impose practice of DRR activities. $65 \%$ of total respondents feel that ignorance and access limitations to DRR education materials create challenges to implementation of DRR.

On a positive note, situation is changing at present as DRR curricula is integrated in some schools. But in most of the schools, DRR education is not included in the curricula, so the students are unaware of the risks and ways of reducing the risks. Inadequate funding for arranging drill and preparedness facilities is another key reason as per $41.67 \%$ respondents.

Sometimes, school authorities are reluctant about giving permission and fund to conduct drill activities according to $50 \%$ of the respondents. The school authorities are ignorant about DRR, they are less concerned about the safety of the students, teachers and staffs. In most of the cases the community members are not invited to the drills or trainings that is organized in the schools. Also, authorities are unenthusiastic about coordinate and collaborate with other stakeholders to arrange drill and preparedness action (according to $83.33 \%$ respondents). That is why some of the areas are lagging behind the know-how of pre and during disaster actions.

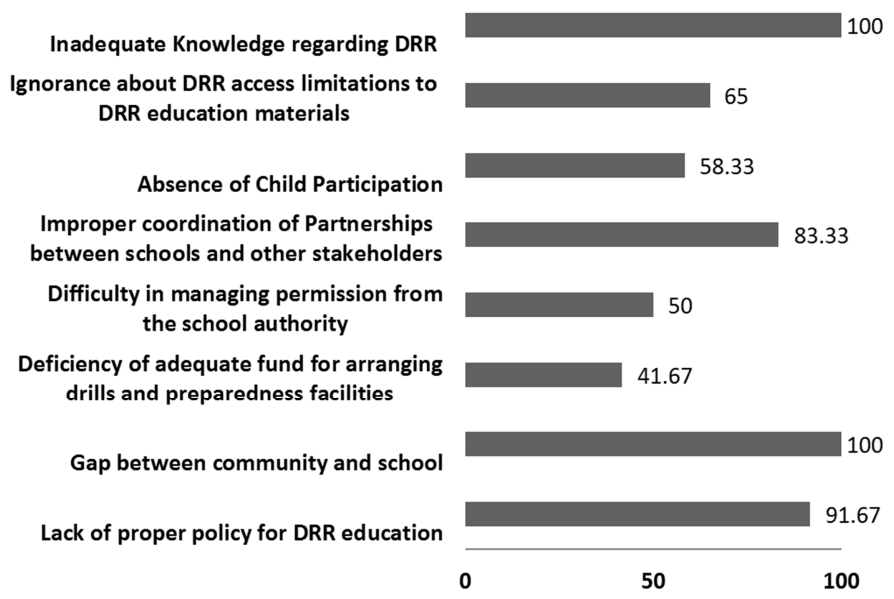

Figure 5. Challenges for DRR implementation in schools of Dhaka city (Source: Field survey, 2020). 
Absence of Child Participation in DRR trainings is another cause for DRR to face challenges in the schools, according to $58.33 \%$ respondents. The trainings are mainly given to only some teachers of the schools mostly in the Government schools.

\section{5. "SWOT" Analysis of DRR Practices in Schools of Dhaka City}

A brief Strength, Weakness, Opportunities and Threats (SWOT) analysis has been conducted to understand the strength, weakness, opportunity and threat of current DRR practices in schools of Dhaka city.

\subsection{School Disaster Management Plan}

School disaster risk management can reduce the vulnerability of the student when they are in school and this plan can make them more resilience in future to combat any kind of natural catastrophes like earthquake or fire incidents. This school disaster risk management group is the combination of School Governing Council and parent-teacher community association. Officials, teacher and community people will generate populace protection safety plan for any disaster which bring safety for all students and teachers. For this concern personnel proposed mock drills and integration in curriculum. School Governing council should have the moto to provide education in safe environment. Parents, Teachers can elect the group who can implement this moto. Proper implementation of the proposed idea can turn a school building into disaster resistant school building and it also improves water and electrical facilities.

Table 2. SWOT Analysis.

\begin{tabular}{|c|c|}
\hline Strength & Weakness \\
\hline $\begin{array}{l}\text { a. DRR education has been integrated in curricula in } \\
\text { some schools } \\
\text { b. Some schools observe annual drill exercise. } \\
\text { c. Some schools have structural DRR measures. } \\
\text { d. Greenery practices are conducted by some schools. }\end{array}$ & $\begin{array}{l}\text { a. Few schools follow proper DRR plan. } \\
\text { b. Most of the schools don't have DRR structural measures which are alarming for disaster. } \\
\text { c. Even though parents and school bodies are concerned about the disaster, there is not enough } \\
\text { implementation of their understandings. } \\
\text { d. Few funding is available for DRR practices in schools. }\end{array}$ \\
\hline
\end{tabular}

\begin{tabular}{|c|c|}
\hline Opport & eats \\
\hline $\begin{array}{l}\text { a. Parents and school bodies are concerned about disaster. } \\
\text { b. Parents and school bodies are aware the necessity of } \\
\text { DRR practice in schools } \\
\text { c. They understand the importance of children safety. } \\
\text { d. GO and NGO are planning to implement DRR practice } \\
\text { in schools. }\end{array}$ & $\begin{array}{l}\text { a. Dhaka is considered one of most vulnerable cities for earthquake and fire incidents; but } \\
\text { most schools lack the interest to follow building code. } \\
\text { b. Several schools can be found in Dhaka city which are unsafe for both children and } \\
\text { teachers as they are not following proper regulations. } \\
\text { c. Despite having no school safety plan (for some schools), parents are obligated to send } \\
\text { their children to schools. }\end{array}$ \\
\hline
\end{tabular}

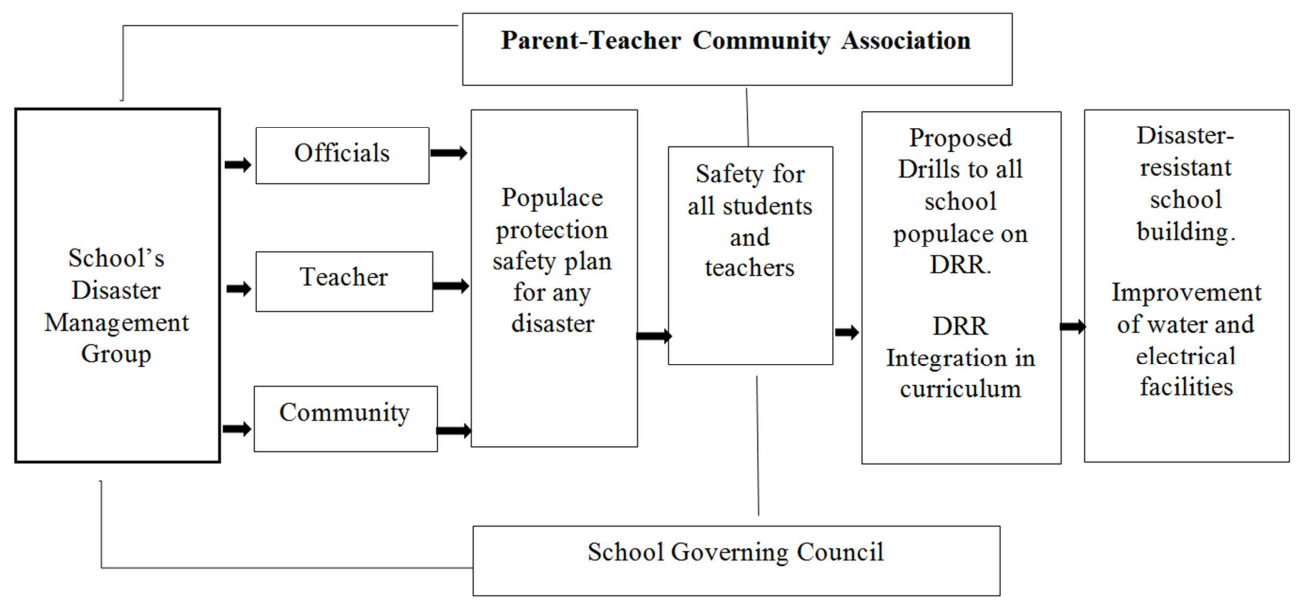

Figure 6. School Disaster Management Plan (Source: Field survey, 2020).

\section{Conclusion}

Disaster occurrence is becoming more frequent and severe with the changing climate of this planet. Dhaka city is one of the world's most risky zone for its geographical location, over population and unplanned urbanization. Disaster Risk Reduction initiatives are taken to reduce the risk and impact of disasters such as including the school as well as community in DRR preparedness practice. The schools play an important and dynamic role in children's life and can help in creating a smart and disaster prepared generation. Schools can also support in creating awareness among the community members and can contribute in the community's emergency operation plan.

The primary focus of the DRR practices and preparedness initiatives in school is to raise awareness and to provide trainings to the teachers, urban volunteers, members of school bodies, staff and parents of the school going children. 
The study has found that there is lack in preparedness initiatives and no emergency management system and no emergency operation plan in practice in the schools of the studied areas in Dhaka city. Although the disaster preparedness knowledge is included in the curricula, there is no legal policy and inadequate training facilities for the teacher and the staffs of the schools.

The study has also found that there is insufficient amount of interaction between the teachers, schools governing body and the community and no structured evacuation and retrofitting system designed for the schools of the studied areas. Only in a small number of schools the DRR related measure is observed in an inadequate quantity.

Children are considered one of the most vulnerable group in any emergency and they can contribute in disaster preparedness of the community. Through community-school interaction a prepared community can be created in the face of any disaster. Any disunion between the community and school and improper school safety measure can worsen the condition of the community during disastrous situation. As Dhaka city lays in the risk prone zone, an unprepared community will increase the vulnerablity and impact.

\section{Acknowledgements}

Authors would like to sincerely acknowledge the cooperation of Center for Higher Studies and Research of Bangladesh University of Professionals for funding this research. Authors also want to mention and thank the students of Department of Disaster and Human Security Management, Bangladesh University of Professionals, Dhaka, Bangladesh.

\section{References}

[1] Akram, A., 2019. Alarming turn of dengue fever in Dhaka city in 2019. Bangladesh Journal of Infectious Diseases, 6 (1), pp. $1-2$.

[2] Amri, A., 2015. Challenges in implementing disaster risk reduction education: Views from the frontline in Indonesia.

[3] Chowdhury, P., 2017. Combating Urban Hazard: A Qualitative Study of Disaster Preparedness in Dhaka, Bangladesh.

[4] Coronavirus spreads to 75 areas in Dhaka, The Daily Star. (2020). Https://www.thedailystar.net/coronavirus-spreads-75areas-in-dhaka-1892218 (accessed April 18, 2020).

[5] COVID-19: impact could cause equivalent of 195 million job losses, says ILO chief, UN News. (2020). https://news.un.org/en/story/2020/04/1061322 (accessed April 17, 2020).

[6] Islam, R., Islam, M. N. and Islam, M. N., 2016. Earthquake risks in Bangladesh: causes, vulnerability, preparedness and strategies for mitigation. ARPN J Earth Sci, 5 (2), pp. 75-90.
[7] McGlade, J., Bankoff, G., Abrahams, J., Cooper-Knock, S. J., Cotecchia, F., Desanker, P., Erian, W., Gencer, E., Gibson, L., Girgin, S. and Hirsch, F., 2019. Global Assessment Report on Disaster Risk Reduction 2019.

[8] Olowu, D., 2010. The Hyogo Framework for Action and its implications for disaster management and reduction in Africa. JAMBA: Journal of Disaster Risk Studies, 3 (1), pp. 303-320.

[9] Reduction, D. R., 2009. UNISDR terminology on disaster risk reduction.

[10] Ronan, K., 2014. Advances and continuing challenges towards HFA2 and post-2015 background chapter.

[11] Sakurai, A., Bisri, M. B. F., Oda, T., Oktari, R. S. and Murayama, Y., 2017, February. Assessing school disaster preparedness by applying a comprehensive school safety framework: A case of elementary schools in Banda Aceh City. In IOP Conference Series: Earth and Environmental Science (Vol. 56, No. 1, p. 012021). IOP Publishing.

[12] Selby, D. And Kagawa, F., 2012. Disaster risk reduction in school curricula: case studies from thirty countries.

[13] Shirin, T., Muraduzzaman, A. K. M., Alam, A. N., Sultana, S., Siddiqua, M., Khan, M. H., Akram, A., Sharif, A. R., Hossain, S. And Flora, M. S., 2019. Largest dengue outbreak of the decade with high fatality may be due to reemergence of DEN3 serotype in Dhaka, Bangladesh, necessitating immediate public health attention. New microbes and new infections, 29.

[14] Steckler, M. S., Mondal, D. R., Akhter, S. H., Seeber, L., Feng, L., Gale, J., Hill, E. M. and Howe, M., 2016. Deformation and seismic hazard associated with the IndoBurman foldbelt from new GPS measurements in Bangladesh. Nature Geosciences.

[15] Stott, C. And Nadiruzzaman, M., 2014. Disaster Risk Reduction in Dhaka City: From Urban Landscape Analysis to Opportunities for DRR Integration. World Vision International.

[16] Strategy, Y., 1994, May. Plan of Action for a Safer WorldGuidelines for Natural Disaster Prevention, Preparedness and Mitigation. In World Conference on Natural Disaster Reduction, Yokohama, Japan (pp. 23-27).

[17] UNISDR, U., 2015, March. Sendai framework for disaster risk reduction 2015-2030. In Proceedings of the 3rd United Nations World Conference on DRR, Sendai, Japan (pp. 14$18)$.

[18] Wallemacq, P., 2018. Economic losses, poverty \& disasters: 1998-2017. Centre for Research on the Epidemiology of Disasters, CRED.

[19] WHO, Disaster Risk Management for Health Fact Sheets: Child Health, 2011. Http://www.who.int/entity/hac/events/drm_fact_sheet_child_h ealth.pdf?Ua=1.

[20] Wisner, B., 2006. A review of the role of education and knowledge in disaster risk reduction. 